\title{
Artículos
}

\section{¿Relocalización o bienestar social? Evaluación de las condiciones de accesibilidad en erradicaciones del Área Metropolitana de Tucumán}

\section{Relocation or social welfare? Evaluation of accessibility conditions in eradications in the Metropolitan Area of Tucumán}

\author{
Ana Laura Castañeda Nordmann* \\ Claudia Fernanda Gómez López**
}

\begin{abstract}
Resumen
El Área Metropolitana de Tucumán (AMeT) evidencia un proceso de gentrificación vinculado a un fuerte proceso de fragmentación socioespacial, manifestado en el crecimiento desigual -en superficie y población- de municipios y comunas (Gómez López, Cuozzo y Boldrini, 2015). El Instituto de Planeamiento, Vivienda y Desarrollo Urbano (IPVDU) lleva a cabo programas de regularización de asentamientos históricos en el AMeT mediante relocalizaciones. En este contexto, la investigación pretende realizar una revisión crítica de dicho proceso, a partir de un análisis multicriterio comparativo de casos, en relación con las estrategias de accesibilidad a los servicios básicos y la calidad de vida de la población.
\end{abstract}

Palabras clave: políticas públicas; servicios básicos; accesibilidad; buenas prácticas urbanas; gentrificación.

\begin{abstract}
The Metropolitan Area of Tucumán (AMeT) is undergoing a process of gentrification linked to intense socio-spatial fragmentation, expressed through the unequal growth -regarding both area and population- of municipalities and communes (Gómez

* Universidad Nacional de Tucumán, Facultad de Arquitectura y Urbanismo, Centro de Estudios del Territorio y el Hábitat Popular. Dirección: Av. Roca 1800, CP 4000, San Miguel de Tucumán, Tucumán, Argentina. Correo: alcastaneda@herrera.unt.edu.ar ORCID: https:// orcid.org/0000-0002-9171-1961

** Universidad Nacional de Tucumán, Facultad de Arquitectura y Urbanismo, Centro de Estudios del Territorio y el Hábitat Popular, Argentina. Correo: claugolo@gmail.com ORCID: https://orcid.org/0000-0002-0575-9388
\end{abstract}


López, Cuozzo and Boldrini, 2015). The Institute for Planning, Housing and Urban Development (IPVDU) is undertaking operations to regularize historic settlements in the ATS through relocations. In this context, this research aims to conduct a critical review of this process, based on a multicriterial, comparative analysis of cases, in relation to the strategies to ensure the accessibility of basic services and quality of life for the population.

Keywords: public policies; basic services; accessibility; good urban practices; gentrification.

\section{Introducción}

El objetivo de esta investigación es revisar críticamente las implicaciones de la relocalización de los asentamientos y las urbanizaciones populares en relación con la accesibilidad a los servicios básicos y a la calidad de vida de la población. Para ello, se comparan estos parámetros en barrios que poseen la situación original (previa a la relocalización) versus la situación actual relocalizada.

Se utilizan como casos de estudio dos asentamientos populares pertenecientes a San Miguel de Tucumán, que fueron relocalizados durante 2014 (Villa Piolín y El Triángulo) a dos nuevos barrios (Manantial I y II) mediante acciones conjuntas entre la administración municipal y el Instituto Provincial de la Vivienda, en el marco del Programa Federal de Urbanización de Villas y Asentamientos Precarios (FedVilla).

El municipio de San Miguel de Tucumán constituye la capital provincial tucumana, ubicada en la región norte argentina (NOA), ${ }^{1}$ y junto con otros cinco municipios y diez comunas rurales, ${ }^{2}$ integra el Área Metropolitana (AMeT) (Mapa 1). El AMeT alcanza una población de 952485.2 habitantes, según el Censo de 2010, y ocupa el quinto lugar en la jerarquía de ciudades nacionales (INDEC, 2010). El suelo urbano tiene una extensión de aproximadamente 20044 ha (Cuozzo, 2018), con una mancha que se extiende por más de $20 \mathrm{~km}$ desde la sierra de San Javier hacia el este del río Salí.

1 Desde el punto de vista jurídico administrativo, Argentina se subdivide en regiones, provincias y departamentos, y éstos en municipios y comunas rurales, según los umbrales de población.

2 Los municipios del AMeT se constituyen por: Yerba Buena, Tafí Viejo, Las Talitas, Banda de Río Salí y Alderetes; y las comunas por: Cevil Redondo, San Javier, La Florida y Luisiana, Colombres, San Andrés, Delfín Gallo, Los Nogales, Manantial, San Felipe y Santa Bárbara, y San Pablo. 
La distribución residencial presenta un claro patrón de concentración por tipo, según las tipologías identificadas: asentamientos informales, urbanizaciones cerradas y viviendas de promoción pública (Mapa 1). Los asentamientos informales se localizan siempre periféricamente en un arco sursureste, en concordancia con el suelo inundable al sur (por debajo de la cota del río Salí) y hacia ambos márgenes del río, al este. Las urbanizaciones cerradas se localizan en un arco pedemontano que se extiende al oeste y noroeste de la mancha, en contacto directo con la sierra de San Javier. La vivienda de promoción pública se ubica en el suelo periférico central, localizado principalmente hacia el norte y sur de la mancha urbana. Cabe destacar los casos de las acciones de mejoramiento barrial y de vivienda de zonas intersticiales del año 1972, que son periféricas a la mancha urbana, aunque a veces tienen una localización más central (Gómez López, Cuozzo y Boldrini, 2015).

La importancia de analizar los casos de San Miguel de Tucumán reside en el papel histórico de éste como enclave del transporte ferroviario (época colonial) y como metrópoli regional en función de la oferta de servicios que concentra (Ministerio del Interior, Obras Públicas y Vivienda, 2014), junto a una accesibilidad polarizada por el área fundacional y su crecimiento, y con bajos niveles de calidad de vida en relación con las demás localidades del AMeT (Castañeda, 2018).

Resulta de interés estudiar la accesibilidad de dichos barrios, antes y ex post, con el fin de analizar la pérdida de inclusión social de la población de bajos recursos que fue relocalizada -supuestamente para mejorar sus condiciones de vida- y, a la vez, observar el desfase temporal entre la dotación estatal de viviendas y la provisión de servicios urbanos.

Este estudio es relevante en el campo académico actual, dado que la accesibilidad a los servicios ${ }^{3}$ constituye un indicador (inherente al Estado

3 La accesibilidad es comprendida desde múltiples dimensiones: educación, sanidad, infraestructura urbana, movilidad pública y centralidad. El acceso a la educación-como medio de transferencia de información y conocimientos- otorga satisfacción en tanto otorga oportunidades sociales y niveles de ciudadanía, no sólo relacionados al ámbito laboral, sino además como estrategia de realización personal y social que posiciona al individuo y a la comunidad como sujeto/s activo/s del proceso de construcción social (Tonón y Castro Solano, 2012). El acceso a la salud otorga satisfacción en cuanto permite a la población vivir de manera sana: obtener posibilidades y libertades (Tonón y Castro Solano, 2012), conexiones entre lo biológico y lo social (movimientos dinámicos entre ambiente, fenotipo y genotipo), procesos dialécticos entre momentos de recreación y conservación; evitar vulnerabilidades epidemiológicas o alteraciones fisiopatológicas y desarrollar defensas físicas y psicológicas (Breilh, 2010; 2013). El acceso a la infraestructura de redes otorga satisfacción, desde su concepción de matriz de desarrollo urbano, a partir de la organización de la funcionalidad de la ciudad (Valenzuela, 2005) mediante la facilitación de aspectos materiales (comunicación, transportación, educación, salud, entre otros), institucionales (reglas formales y restricciones para dar forma a los hábitos sociales) y

Estudios Demográficos y Urbanos, vol. 35, núm. 1 (103), enero-abril, 2020, pp. 185-214 


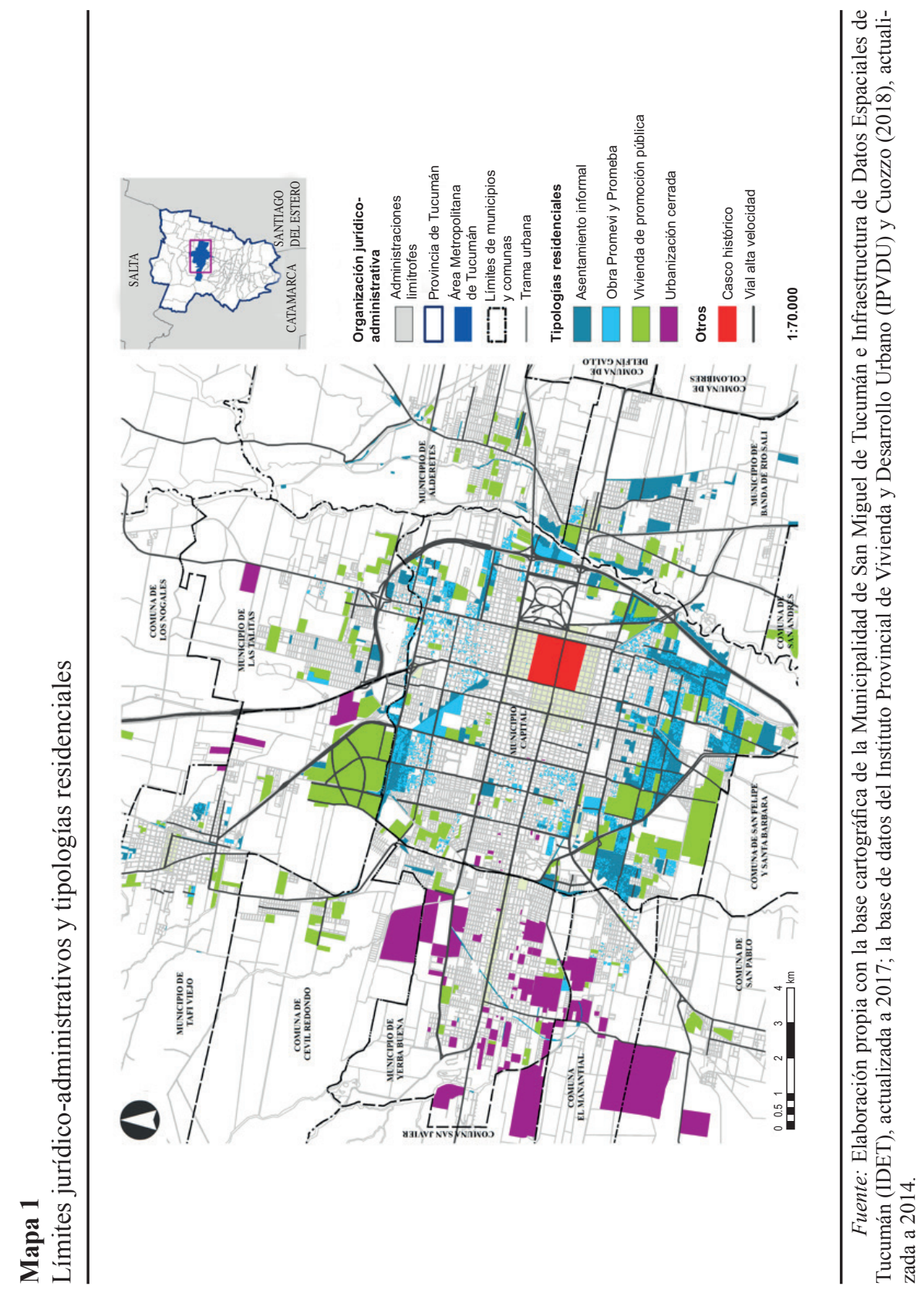


desde su representación como mandato) de la calidad de vida de la población en tanto permite a ésta materializar sus necesidades (Pardo, 2005, citado en Obregón Biosca y Betanzo Quezada, 2015, p. 63) y le otorga bienestar material y emocional. Este último se asocia con las relaciones armónicas familiares, sociales y ambientales, con las actividades productivas y de seguridad, así como con la autoestima social y la integración comunitaria (Velázquez, 2001; Ardila, 2003; Satriano, 2006; Hernández Aja, 2009; Tonón y Castro Solano, 2012).

La calidad de vida involucra como marco de referencia parámetros culturales y sociales de la época (Schwartzmann, 2003). En este contexto, el bienestar social constituye una dimensión básica (dinámica, continua y emergente) de construcción social para la concreción de la calidad de vida urbana, que se asocia a la vez a la concepción -ideográfica y/o nomotéticade condición, oportunidad de vida y satisfacción relativa con la vida (de garantía institucional). Ésta viene dada de la provisión material de servicios públicos, los cuales dan respuesta a las necesidades y se asumen como imprescindibles en nuestro entorno sociocultural para generar determinado bienestar psicosocial (Hernández Aja, 2009; Guevara, Domínguez, Ortunio, Padrón y Cardozo, 2010; Urzúa y Caqueo Urízar, 2012; Tonón y Castro Solano, 2012).

A su vez, la localización espacial de los servicios públicos condiciona la calidad de vida en tanto su distribución socioespacial estatal logre equidad de oferta y demanda, externalidades positivas y vinculaciones con la deman-

personales (Barajas Bustillos y Gutiérrez Flores, 2012); sumado a su capacidad de hacerse cargo de sucesos en función de una demanda específica de la población (Figueroa, 2013) y a la plusvalía y al valor agregado que otorgan (Valenzuela, 2005). El acceso al transporte público, particularmente, entendido como elemento de servicio funcional urbano cotidiano de desenvolvimiento y aceleración de la vida social, otorga satisfacción en tanto posibilita el traslado simultáneo de grandes volúmenes de personas por corredores de gran densidad de demanda - desde un aumento del tiempo invertido- al trabajo, centros de abastecimiento y consumo, equipamientos (educativos, sanitarios, recreativos, entre otros), y la realización de diversas actividades (Figueroa, 2005; Rodríguez Vignoli, 2008; Navarrete Rodríguez y Andrade Vallejo, 2010; Lange Valdés, 2011; Dangond Gibsone, Jolly, Monteoliva Vilches y Rojas Parra, 2011). A su vez, como herramienta de control y organización del espacio, aporta a los procesos de transformación, reestructuración y expansión urbana; y desde la relación con el entorno por el que se circula, a la conectividad de las diferentes áreas y la producción del espacio urbano, a través de estimular la concentración de actividades y de intervenir en la valorización diferencial del suelo (Gutiérrez, 2000; Figueroa, 2005; Lange Valdés, 2011; Blanco, Bosoer y Apaolaza, 2014). El acceso a las centralidades otorga satisfacción desde su constitución como área destacada y de referencia focal a partir de la concentración de actividades (oferta de servicios y de trabajo) y relación con otras áreas, desde una función de conectividad, integración y convergencia (Beuf, 2011; Mayorga y Fontana, 2012; Porro y Mesa, 2016), aunque particularmente desde su rol de otorgar mayores condiciones de habitabilidad (Prado Ríos, 2001). 
da (Buzai y Baxendale, 2008). La importancia de incluir a los servicios en el crecimiento urbano radica, entonces, en que éstos no sólo asientan la parcelación y perfeccionan la edificación (Magrinyà Torner, 2005), sino que además mejoran la calidad de vida de la población (Hernández Aja, 2009).

En este punto entran en juego dos variables más que se consideran de importancia en el impacto en los niveles de satisfacción de la población en relación con la dotación de servicios urbanos: por un lado, el acceso a la identidad urbana, que implica la apropiación de los individuos sobre su medio a lo largo del tiempo, su participación, satisfacción de necesidades y modos de relación en el constructo social y en la producción de la ciudad (Hernández Aja, 2009); y por otro, las acciones del gobierno o políticas públicas asociadas al nivel de respuesta oficial de las decisiones estatales a las necesidades sociales y respeto de los derechos humanos desde el reconocimiento sociopolítico y sociocultural (Tonón y Castro Solano, 2012). La presente investigación se focaliza en estas últimas consideraciones.

En el año 2000, Hábitat II definió a la ciudad inclusiva como "el lugar donde cualquier persona, independiente de su condición económica, sexo, edad, raza o religión, puede participar productiva y positivamente en las oportunidades que le ofrece la ciudad".

La exclusión en las ciudades afecta dos derechos básicos: el ejercicio social del "derecho a la ciudad" (la exclusión de bienes y servicios urbanos básicos como vivienda, agua, cloaca, transporte) y el "derecho a ser ciudadano" (la exclusión de la representación política y la toma de decisiones) (Wainstein Krasuk y Brandariz, 2014).

De acuerdo con los preceptos de Hábitat II, una política de inclusión social no puede circunscribirse exclusivamente a la mejora de la vivienda, también debe contemplar la accesibilidad de los individuos a los bienes y servicios urbanos, así como también su participación en el proceso de definición y gestión urbana.

De modo que entender a los equipamientos e infraestructura de redes que persiguen el bienestar social como indicadores de acceso urbano, implica asociarlos a las condiciones y niveles de satisfacción (calidad de vida) o carencia (pobreza) relacionados al bienestar físico, psicológico, social, material y ambiental (Velázquez, 2001; Longhi, Bolsi, Velázquez, Paolasso y Celemín, 2015).

Si bien la población que se encuentra en condiciones de pobreza-desde una perspectiva socioeconómica de carencia- no alcanza los umbrales mínimos establecidos de satisfacción de las necesidades básicas referidas al acceso residencial confortable, educación y alimentación adecuada, ni en los aspectos locacionales, ambientales y de acceso público a determinados ser- 
vicios, estas carencias pueden condicionar los niveles de satisfacción respecto a la mejora de las condiciones de vida (Velázquez, 2001; Velázquez y Celemín, 2013).

La urbanización implica otorgar a las parcelas el acceso físico a equipamientos comunitarios, redes de agua y saneamiento, electricidad, gas y vialidad para el transporte mecanizado. Sin embargo, en las experiencias urbanas actuales, primero se produce la edificación y luego se desarrollan -de manera gradual en una adaptación espacio-tiempo- los servicios urbanos (Magrinyà Torner, 2005).

En nuestro contexto latinoamericano, la dotación gradual de los servicios depende del poder adquisitivo de los usuarios, puesto que gran parte de ellos corre por cuenta directa de los vecinos (en forma privada). En los terrenos privados de valor alto, los servicios se producen casi de manera simultánea con el parcelamiento o loteo; en las promociones públicas de vivienda, la dotación se produce en la medida en que el Estado los incluye en el plan de urbanización original o en planes futuros; mientras que en las urbanizaciones marginales permanecen ausentes, de no mediar una acción concreta para su provisión (Gómez López, 2001).

En Latinoamérica, el giro en la política social en las ciudades ocurre a lo largo de las décadas de los ochenta y los noventa, y llega al interior del país de la mano de estos primeros planes de actuación en las urbanizaciones populares. Los mismos buscan "urbanizar" los asentamientos populares con acciones que van desde la regularización dominial, la provisión de infraestructura básica y la construcción de pie de casa, entre otros.

El cambio en la concepción de las políticas urbanas se debe a la paulatina toma de conciencia al respecto en el ámbito mundial, cuando se empezó a pensar en políticas destinadas a la mejora integral del hábitat desde la concepción de la vivienda en términos de servicios habitacionales y no como un producto. Servicios que son concebidos, además, como un proceso de construcción colectiva mediante la participación y la integración efectiva de la población al entramado social urbano. Estas políticas han sido aceptadas por el mundo institucional de los gobiernos locales y por la academia en Latinoamérica, y difundidas como ejemplos de "buenas prácticas urbanas". ${ }^{4}$ Las políticas de intervención para el mejoramiento del hábitat, inscritas en la filosofía de las "buenas prácticas urbanas", se difundieron y multiplicaron en la década del año 2000.

En Argentina, las políticas sociales relacionadas con la pobreza, derivadas de las políticas públicas implementadas desde la década del noventa,

4 Ejemplos de buenas prácticas urbanas son el "Favela barrio", de Mario Jáuregui.

Estudios Demográficos y Urbanos, vol. 35, núm. 1 (103), enero-abril, 2020, pp. 185-214 
destinaron gran parte del presupuesto a llevar a cabo programas al respecto -como mecanismos de control social y asistencialismo-, los cuales tuvieron resultados ineficaces o poco satisfactorios dada la insuficiencia de intervenciones, la inequidad en la distribución de los recursos públicos, el aumento de la fragmentación social (en términos de marginalidad, violencia social, exclusión y ausencia de elección) y la disminución en la calidad de vida (con respecto a la incapacidad de funcionamiento y de acumulación de bienes y recursos) (Satriano, 2006).

Dichas políticas públicas profundizaron determinados procesos urbanos, como el denominado gentrificación o aburguesamiento, que comenzó a manifestarse críticamente desde mediados del siglo XX y se difundió - desde Norteamérica al resto del mundo- entre las décadas del sesenta y el setenta, a partir de las políticas de desarrollo urbano que han buscado -particularmente desde finales del siglo XX- revitalizar funcionalmente los centros degradados y desplazar a los grupos de población de altos ingresos hacia éstos para mejorar sus condiciones físicas y socioeconómicas, así como reestructurar demográfica y socioculturalmente los centros urbanos (Smith, 2012; Manrique Gómez, 2013).

Este proceso, de inversión y desinversión, de transformación temporal y espacial de los patrones tradicionales de crecimiento urbano (Blanco, Bosoer y Apaolaza, 2014), ha generado segregación social dada la expulsión de la población de menores ingresos que residía en dichas áreas (Boldrini y Malizia, 2014) y se traduce en un intercambio de niveles socioeconómicos y de clases sociales entre áreas, con ventajas simbólicas localizativas para la nueva población residente en el sector central y desventajas para la periférica (Blanco, Bosoer y Apaolaza, 2014). ${ }^{5}$

En la primera situación, las ventajas previas al traslado se relacionan con el alto nivel de consolidación del sector y su entorno en términos de accesibilidad y proximidad, al poseer oferta variada de transporte público, posibilidad de recorridos cortos para la realización de actividades y traslado a pie, reducción de tiempos de movilidad (vías rápidas de circulación), mayor cercanía a centros metropolitanos (lugares de encuentro social, trabajo y recreación) y de consumo de bienes y servicios (Blanco, Bosoer y Apaolaza, 2014). Las ventajas posteriores al traslado están asociadas a la revalorización del sector en carácter y aspecto, la alteración de sus niveles de consumo según la demanda de los nuevos residentes y el incremento de la rentabilidad del suelo a partir del aumento de la plusvalía urbana (Manrique Gómez, 2013).

5 Blanco, Bosoer y Apaolaza (2014) sostienen que los estudios referidos a caracterizar las nuevas condiciones de movilidad y acceso de la población desplazada por procesos de gentrificación son escasos. 
En la segunda situación, las desventajas previas al traslado se relacionan con la condición de vulnerabilidad de la población en cuanto a su escasez de recursos, sumada a la nula o muy poca accesibilidad y al aislamiento debido al alejamiento del sector de las vías rápidas de circulación, y a la insuficiente dotación de redes de transporte público, así como de centros principales de servicios. Las desventajas posteriores al traslado están asociadas a la exclusión y segregación social como resultantes de la dificultad de movilidad y de la dependencia del transporte vehicular privado (que en la mayoría de los casos no poseen), al incremento de los costos de vida por la lejanía y al aumento de las distancias para realizar las actividades cotidianas, al menor acceso a los centros principales de servicios y a la pérdida de identidad (apropiación) por la sustitución del hábitat residencial y del capital social (Manrique Gómez, 2013; Blanco, Bosoer y Apaolaza, 2014).

En Tucumán, los primeros planes de carácter asistencialista (políticas de intervención para mejoramientos del hábitat) datan del periodo del advenimiento democrático en la década de los ochenta, y fueron ejecutados mediante programas focalizados en los sectores vulnerables, implementados inicialmente por el Instituto Provincial de Vivienda (IPV), con planes como Dignificar la Vida o Plan Arraigo, y más recientemente con Promeba (Programa de Mejoramiento Barrial), Promevi (Programa de Mejoramiento de Vivienda), o líneas de acceso al crédito municipal para mejoras del hábitat, como Municipio más Cerca (Gómez López, 2001; Boldrini, 2011).

Producto de la manera en que se ha producido el crecimiento metropolitano de Tucumán, sin control y regulación urbana, se detectan, entre otros procesos, el de gentrificación vinculado a un fuerte proceso de fragmentación socioespacial, manifestado en el crecimiento desigual -en cuanto a superficie y población- de municipios y comunas (Boldrini y Malizia, 2014; Boldrini, Del Castillo y Malizia, 2014; Gómez López, Cuozzo y Boldrini, 2015) y en la fuerte concentración de obra pública destinada a los sectores medios (Gómez López, Cuazzo y Boldrini, 2015).

Entre las líneas de actuación del Instituto Provincial de Vivienda y Desarrollo Urbano (IPVDU, antes IPV) se llevan a cabo, en forma conjunta con el municipio de San Miguel de Tucumán, acciones de relocalización de asentamientos populares de las que surgen los casos de estudio que se presentan en este artículo. 


\section{Metodología}

Como proceso metodológico, en este trabajo se realiza un análisis comparativo mediante cuadros y mapas, valorando la accesibilidad a determinados servicios urbanos en los casos seleccionados. Para ello, se propone una metodología multicriterio, en un entorno de sistemas de información geográfica (SIG), que posibilita el manejo de numerosas variables y, a través de un proceso de jerarquización de las mismas, se obtiene el modelo acorde con el objetivo propuesto.

En primer lugar, se determinaron y caracterizaron los barrios en los que se emplazan los casos de análisis: Villa Piolín y El Triángulo, asentamientos populares relocalizados durante 2014 en dos nuevos barrios ubicados en Manantial I y II, en San Miguel de Tucumán. Para ello se trabajó con información aportada por el Instituto Provincial de Vivienda y Desarrollo Urbano de Tucumán (IPVDU), extractos de noticias en línea y diagnósticos metropolitanos recientes provenientes de la base de datos del Centro de Estudios sobre el Territorio y el Hábitat Popular, de la Facultad de Arquitectura de la Universidad Nacional de Tucumán (CETyHaP).

En segundo lugar, se analizó la localización y la cobertura de los equipamientos de salud, educación, centros de servicios de mayor jerarquía, ${ }^{6}$ redes de agua, cloaca, gas, vías de asfalto y transporte público; y la cercanía a áreas con aglomeración de servicios de alcance metropolitano y colectoras de redes de transporte público. ${ }^{7}$ Dicho análisis se llevó a cabo mediante un cuadro comparativo que contiene el resultado del análisis de cada variable $\mathrm{y}$ de los casos de estudio en tres rangos de alcance que exponen los distintos niveles de cobertura: 0-200 metros (óptimo), 200-500 metros (aceptable) y 500-2000 metros (deficitario) (Cuadro 1).

El análisis se aborda desde el cálculo de la superficie de suelo urbano con cobertura de las variables agua, cloaca, gas, vía de asfalto y transporte público en relación con un buffer definido para cada rango. ${ }^{8}$ Para ello, se asignó un radio de 60 metros a las tres primeras redes de infraestructura, en

6 Se denominan centros de servicios metropolitanos o de mayor jerarquía a aquellas áreas con aglomeración de dotaciones que atraen población y actividades desde toda el área metropolitana. Están constituidas por bancos, centros de telefonía móvil, sedes de gestión y manejo de infraestructuras, sedes de atención social, centros culturales, teatros, cines, centros de entretenimiento, universidades, centros médicos especializados, entre otros (Castañeda, 2018).

7 Se denominan colectoras a aquellas vías de circulación vehicular que contienen más de cinco líneas o recorridos de transporte público. Su importancia reside en que garantizan la movilidad pública poblacional desde el barrio hacia los distintos sectores de la ciudad.

8 El primer rango de 0 a 200 metros posee una superficie de $0.125 \mathrm{~km}^{2}$; el segundo, de 200 a 500 metros, tiene $0.659 \mathrm{~km}^{2}$; y el último, de 500 a 2000 metros, alcanza $11.78 \mathrm{~km}^{2}$.

Estudios Demográficos y Urbanos, vol. 35, núm. 1 (103), enero-abril, 2020, pp. 185-214 


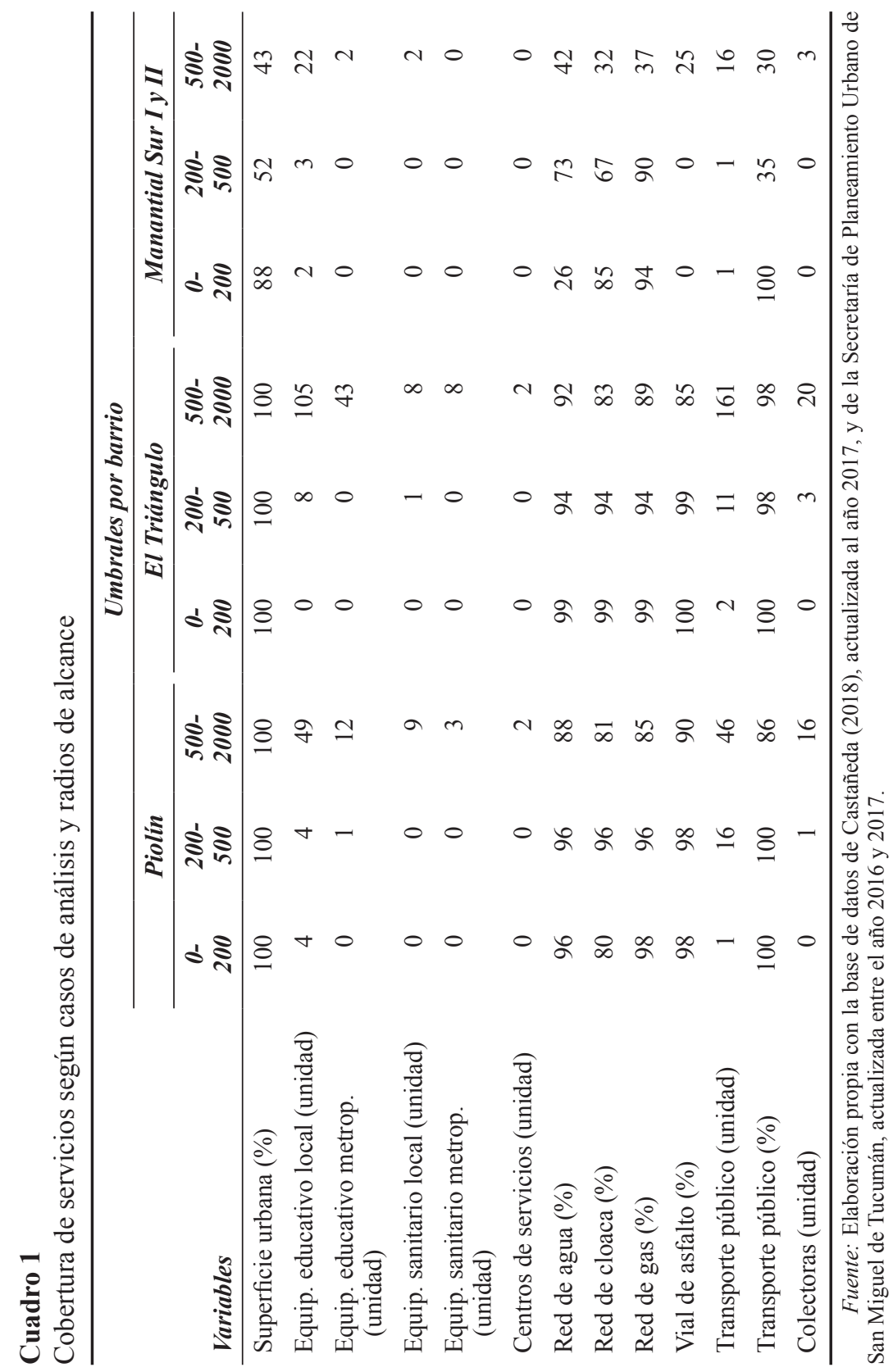


tanto éste constituye la distancia aproximada de acceso de la cañería domiciliaria en cada manzana; de 10 metros en el caso de la vía, ya que constituye el ancho de calle predominante; y de 200 metros en cuanto al transporte público, al tratarse de un área precaria que posee mayor fricción y requiere de menor distancia admisible para el recorrido a pie.

Las variables educación, salud, líneas de transporte público, colectoras y áreas con servicios metropolitanos se consideran desde su cobertura en términos unitarios. En el caso de las colectoras de transporte público, se considera la distancia mínima al barrio por la vía accesible.

Los equipamientos educativos y sanitarios se diferencian, según su radio de influencia de uso, en locales y metropolitanos. ${ }^{9}$

La base de datos de las variables educación, salud, centros con servicios metropolitanos y transporte público de pasajeros se obtuvieron de un trabajo previo realizado por Castañeda (2018), y se actualizaron al año 2017; $;^{10}$ mientras que la información sobre redes de agua, cloaca, gas y vialidad de asfalto proviene de la Secretaría de Planeamiento Urbano de la Municipalidad de San Miguel de Tucumán, actualizada entre 2016 y 2017.

En tercer lugar, se analiza espacialmente la accesibilidad física de la población para la localización original y para la del traslado (Mapa 3). Para ello, sobre la base del SIG, se llevó a cabo el proceso operativo multicriterio, en el cual se convirtieron las variables a formato ráster, se elaboraron mapas de proximidad de cada una (distancia o densidad), se normalizaron de 0 a 1 para equiparar las unidades de medida, se jerarquizaron mediante ponderaciones y, finalmente, a partir del ordenamiento de los pesos de los pixeles de las variables ponderadas, se obtuvo la modelización según el objetivo propuesto (Contreras y Pacheco, 2007), en este caso, los niveles de acceso de cada área.

La estimación de las ponderaciones para cada variable que compone el análisis (Cuadro 2) resulta de una propuesta de las investigadoras, que tomaron la decisión de otorgar mayor peso a las variables transporte público, colectoras de transporte, vialidad de asfalto, equipamientos y centralidades metropolitanas, en tanto las mismas inciden en el flujo de personas que se movilizan hacia el resto de las localidades del AMeT. Se otorgó valor intermedio a las redes

9 Se denominan equipamientos locales a aquellos que poseen un radio de influencia de uso próximo al mismo (aproximadamente 500 metros en tanto se entiende como la distancia máxima que un individuo está dispuesto a recorrer a pie); y equipamientos metropolitanos a aquellos cuyo umbral excede el radio local de uso y se extiende hacia otras áreas del aglomerado metropolitano (Castañeda, 2018).

10 En el caso se los centros con servicios metropolitanos, también se utilizó como antecedente un trabajo previo realizado por Castañeda, Malizia y Boldrini (2018), en el que se diferenciaron áreas específicas dentro del AMeT con centralidad de actividades. 


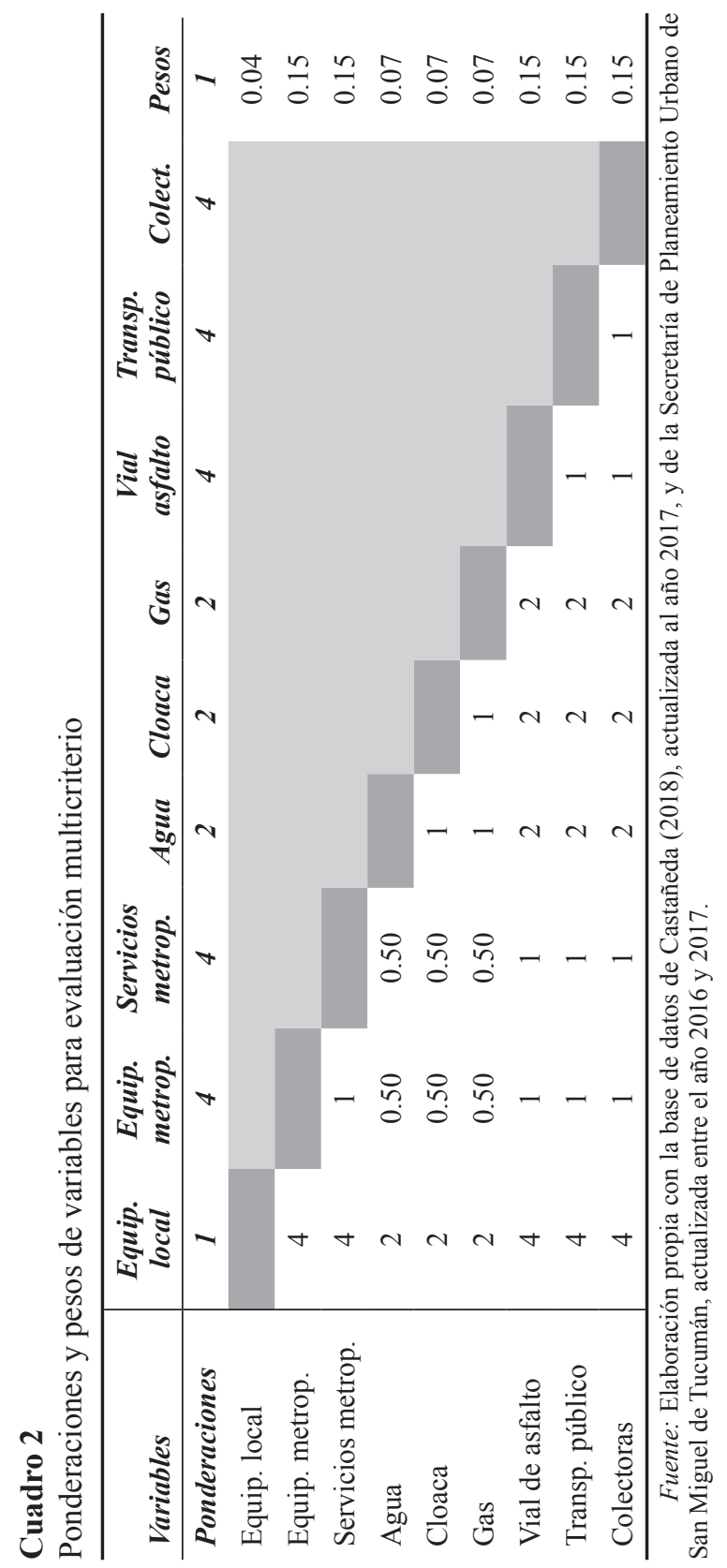


de agua, cloaca y gas por su necesidad de uso para el funcionamiento diario y la salubridad de los hogares; y la menor ponderación de peso fue la de los equipamientos locales (sin disminuir su incidencia en relación con las demás) en tanto polarizan a la población en un entorno menor.

Del análisis se obtuvieron graduaciones de accesibilidad que se reclasificaron en cinco niveles: muy alto, alto, intermedio, bajo y muy bajo. Por último, se analizan los resultados y se elaboraron las conclusiones de la investigación.

\section{Casos de análisis}

El Triángulo -también conocido como El Triangulito- constituye un asentamiento informal relocalizado en mayo de 2014 (lo cual estaba previsto para 2012), data de la década del cincuenta y se encuentra ubicado en el barrio La Ciudadela de la capital provincial, entre las calles Simón Bolívar y Campo de las Carreras (a la altura del 1800); cuenta con una extensión de manzana urbana que suma una superficie de 0.65 ha. En dicho barrio residían entre 43 y 56 familias en condiciones de marginalidad y hacinamiento, en viviendas amontonadas (de madera o bloques de cemento), y el sistema de cloaca se componía por acequias que cruzaban las casillas y desembocaban en las calles (La Gaceta, 2003; 2014). El subsidio a las familias contemplaba el traslado al barrio Manantial Sur mediante el financiamiento de la Subsecretaría de Desarrollo Urbano y Vivienda del Ministerio de Planificación Federal y un abono mensual nulo por la propiedad de las nuevas viviendas (La Gaceta, 2013).

El predio, perteneciente a la Municipalidad de San Miguel de Tucumán, fue desocupado para la construcción de una plaza pública o parque temático llamado "La Ciudadela" -por ordenanza aprobada en 2013-, en homenaje al bicentenario y a José de San Martín. Aunque a un mes del traslado de las familias los vecinos sostenían que comenzaba a crecer un basural y que se requerían trabajos de limpieza, construcción de cordón cuneta y alumbrado público (La Gaceta, 2003; 2014; 2014a), al día de hoy se observan trabajos de construcción de caminería y equipamiento.

Ángela Riera - conocido como Villa Piolín-constituye un asentamiento informal relocalizado en noviembre de 2014, que data de la década del setenta y se encuentra ubicado en la capital provincial, entre las calles Crisóstomo Álvarez y San Lorenzo (a la altura de la avenida Mate de Luna 2800), con una extensión de dos manzanas urbanas que suman una superficie de 1.5 ha. En dicho barrio residían aproximadamente 150 familias en condiciones 
de marginalidad y hacinamiento, en viviendas precarias (fundamentalmente de madera) y con circulación angosta y laberíntica (La Gaceta, 2010; 2014b; 2014c; 2014d). El predio, perteneciente a una empresa privada, era objeto de litigio entre ésta y la provincia desde el año 1988. El mismo fue expropiado en 2014 (Fotos 1 y 2), con objeto de ser ocupado como espacio verde o servicio público, por sanción de la Sala III de la Cámara Civil y Comercial, que ordenó a la provincia el pago de casi dos millones, valuados en australes, pero actualizados a la moneda peso en dicho año (La Gaceta, 2014b; 2014d; 2014e).

Cabe destacar la accesibilidad y articulación de estos asentamientos con el resto de la ciudad, puesto que ambos se encontraban incluidos en la mancha urbana de la ciudad desde antes de los ochenta y contaban con vialidades completas.

El área de relocalización es una zona de expansión reciente de la ciudad, cuya existencia se registra a partir del 2010. Físicamente se encuentra separada del conglomerado por la presencia del canal de desagüe sur, vinculado con el centro de la corona metropolitana denominado Manantial, perteneciente a la comuna rural homónima.

La urbanización Manantial Sur es un emprendimiento habitacional del IPVDU, localizado originalmente en la comuna Manantial, cuya jurisdicción pasó al municipio de San Miguel de Tucumán desde la habilitación del me-

\section{Foto 1}

Desocupación forzosa del barrio Ángela Riera

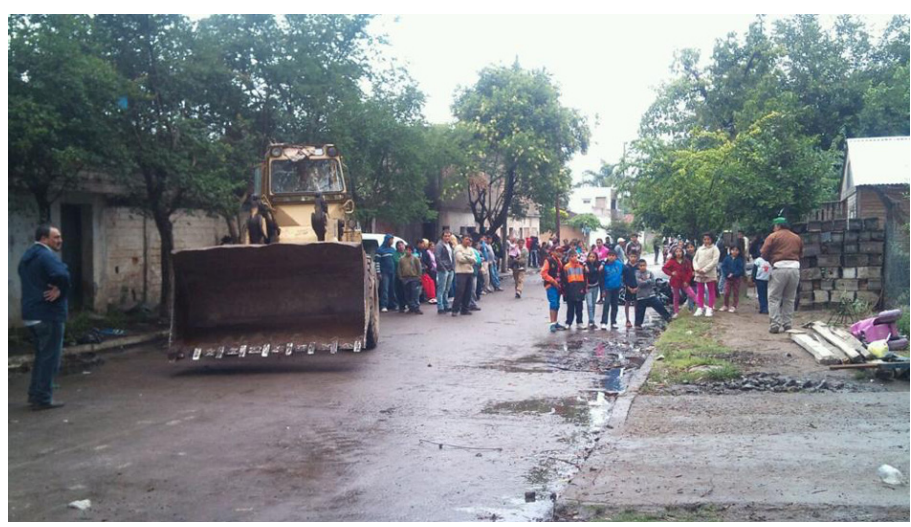

Fuente: Base de datos La Gaceta, 3 de noviembre de 2014.

Estudios Demográficos y Urbanos, vol. 35, núm. 1 (103), enero-abril, 2020, pp. 185-214 


\section{Foto 2}

Uso actual (plaza) en el exasentamiento Ángela Riera

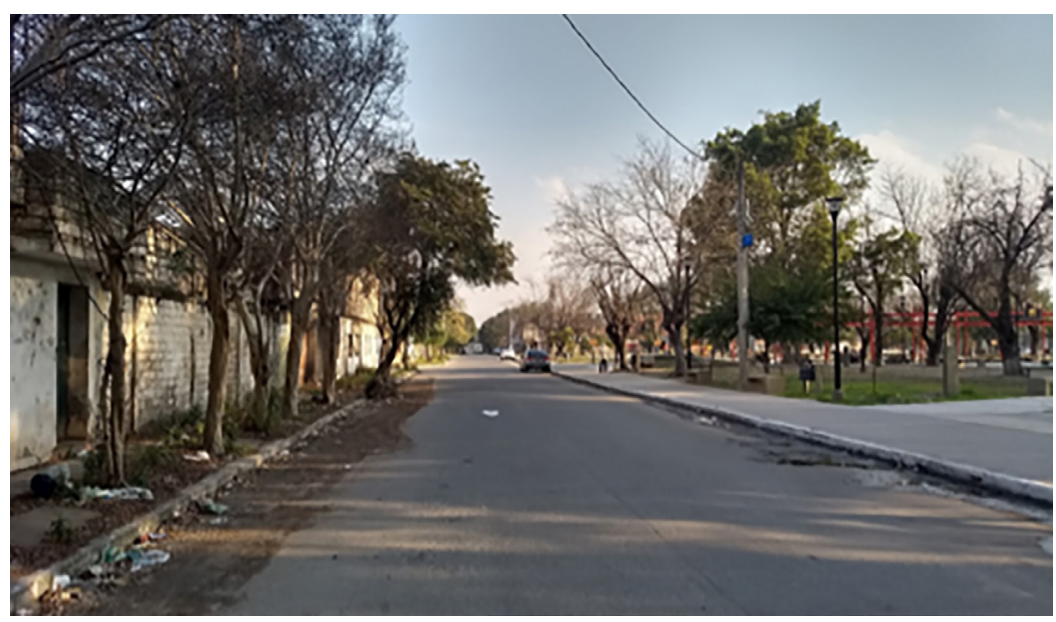

Fuente: Fotografía de las autoras, 2018.

gaemprendimiento. El acceso se produce por la expansión de las avenidas Colón, Alem y Coronel Zelaya (para continuar la trama urbana de la capital). Está destinado a la relocalización de distintos asentamientos informales del AMeT, con una capacidad de acogida para 2500 familias de escasos recursos que habitan en condiciones de precariedad, riesgo ambiental y niveles deficitarios de cobertura de redes de servicios (1 500 viviendas con tres dormitorios, 1000 con dos, y dentro de éstas se dejaron reservas para la población con discapacidad) (Olivera, 2013; Comunicados de Prensa IPVDU, 2013; Secretaría de Estado de Comunicación Pública del Gobierno de Tucumán, 2016). La obra general fue presupuestada en $\$ 751919$ 432, dividida en cuatro sectores de viviendas; aunque al año 2013 el avance de las obras fue del 9.38\%, con una inversión de \$70 573691 (Olivera, 2013).

Las etapas I y II, correspondientes a la relocalización de los asentamientos Villa Piolín y El Triángulo (Foto 1), integran un área que posee aproximadamente $13.30 \mathrm{ha}$, con lotes individuales que superan los $270 \mathrm{~m}^{2}$. En la relocalización, ambos asentamientos contaban -según IPVDU-con unidades con cocina y calefón (calentador de agua), red vial, gas natural, agua potable, desagües cloacales y pluviales, energía eléctrica, caminerías y arbolado. Se tenían previstas, a su vez, reservas para equipamientos comunitarios, educa- 
tivos, sanitarios, deportivos, recreativos, espacios verdes (plazas y un parque a escala urbana), líneas de transporte público de pasajeros, construcción de avenidas y calles principales de 28 a 30 metros (con carácter de bulevares arbolados) y conexión a las redes colectoras ya existentes (Olivera, 2013; Comunicados de Prensa IPVDU, 2013; La Gaceta, 2014b; Secretaría de Estado de Comunicación Pública del Gobierno de Tucumán, 2016).

A un año del traslado, las familias comenzaron a reclamar la falta de servicios de recolección de residuos (tarea de la capital), que deriva en el derrame de basura por las avenidas que bordean la urbanización o en terrenos baldíos, así como la falta de desmalezamiento, la escasa iluminación de calles (según IVPDU, esto se debe al robo permanente), la insuficiencia de transporte público (para llegar a las paradas más cercanas hay que atravesar interminables pasillos de casas precarias), hospitales, centros asistenciales públicos de salud, red de agua potable (las dos estaciones de bombeo construidas para ese emprendimiento se encuentran sin funcionar), espacios verdes (sin convertirlos en parques o jardines) y la existencia de focos de contaminación y malos olores por las cámaras de inspección (registros) sin tapa (las provistas con la vivienda original fueron sustraídas), de las que brotan aguas contaminadas constantemente (La Gaceta, 2014b; Contexto, 2016).

En el caso de la población relocalizada de Villa Piolín, en el año 2015 aún esperaban equipamientos de salud, pista de atletismo, cancha de básquet, iluminación vial, vigilancia (ante la creciente inseguridad del barrio) y el parque prometido; de este último se realizaron trabajos aislados como nivelación de suelo y construcción de veredas perimetrales, bancos y calles peatonales (Tucumán Primicias, 2015). La población relocalizada en El Triángulo expresó su descontento por recibir módulos habitacionales mínimos que no pueden ampliar porque carecen de medios económicos suficientes y por las grandes distancias que incrementan notablemente los costos de los desplazamientos diarios de las familias (La Gaceta, 2014).

Paradójicamente, ante el reclamo vecinal, el titular del IPVDU afirmaba que dicha institución cuenta con un plan para remediar la urgencia, argumentando problemáticas de largo plazo como la alta concentración poblacional y la falta de infraestructura básica en las zonas urbanizables. Sostenía, además, que la planificación de estos nuevos barrios y su posterior concreción generarían mayor inclusión social y plusvalías urbanísticas en las áreas de influencia por la dotación de redes de infraestructura, que propiciarían la instalación de emprendimientos privados que revalorizarían el barrio (Olivera, 2013; Municipalidad de San Miguel de Tucumán, 2016). 


\section{Resultados}

\section{Cobertura de servicios básicos, cercanía a colectoras y a centralidades}

Como primera observación, se constata que en los dos asentamientos originales el 100\% del suelo comprendido en los tres radios analizados $(200 \mathrm{~m}$, $500 \mathrm{~m}$ y $2000 \mathrm{~m}$ ) (Mapa 2) es urbano; mientras que en el sitio de relocalización el suelo urbano es mayoritario sólo en el primer radio (200 m), siendo minoritario en los otros. Esta situación describe una profunda diferencia en relación con la condición urbana actual y potencial en la localización original respecto a la de destino.

En cuanto a los equipamientos de educación, salud y centros de servicios metropolitanos, se evidencia una clara disminución de la oferta respecto a la situación de origen. En el caso de la educación y la salud, la cobertura en la relocalización no alcanza, en el mejor de los casos, a la tercera parte de la que se tenía en el barrio de origen. Respecto a los centros de servicios, Villa Piolín y El Triángulo poseen dos en sus cercanías, localizados a una distancia mínima de $1300 \mathrm{~m}$ en el primer caso y $700 \mathrm{~m}$ en el segundo (por calle de asfalto); mientras que Manantial no posee ninguno, con una distancia mínima de $2700 \mathrm{~m}$ (mayoritariamente por calle de ripio -cascajo-).

Con las redes ocurre algo similar. En cuanto a la red de agua en la relocalización, la cobertura es notablemente menor; mientras que en el caso de las cloacas y el gas, la cobertura es similar a la del lugar de origen.

La red viaria de asfalto en Manantial posee una situación crítica en relación con los barrios de origen, ya que éstos tienen casi el 100\% de su red pavimentada, mientras que el primero se encuentra cubierto hasta el radio de $500 \mathrm{~m}$ por calles de tierra y ripio.

Respecto a la cobertura del transporte público, se observa que la oferta de servicios disminuye notablemente en la situación de relocalización. En el caso del Piolín, éste posee 16 colectoras con una distancia de $150 \mathrm{~m}$ la más cercana (avenida Mate de Luna); El Triángulo tiene 20 con una distancia de $170 \mathrm{~m}$ la más cercana (calle Lavalle); y Manantial III, con una distancia mínima de $2200 \mathrm{~m}$ y por calle de ripio (ruta provincial 301), ya que las dos más próximas (avenidas Colón e Independencia) se encuentran inaccesibles por la presencia del canal, que constituye una barrera física insalvable sin obra civil mediante. 


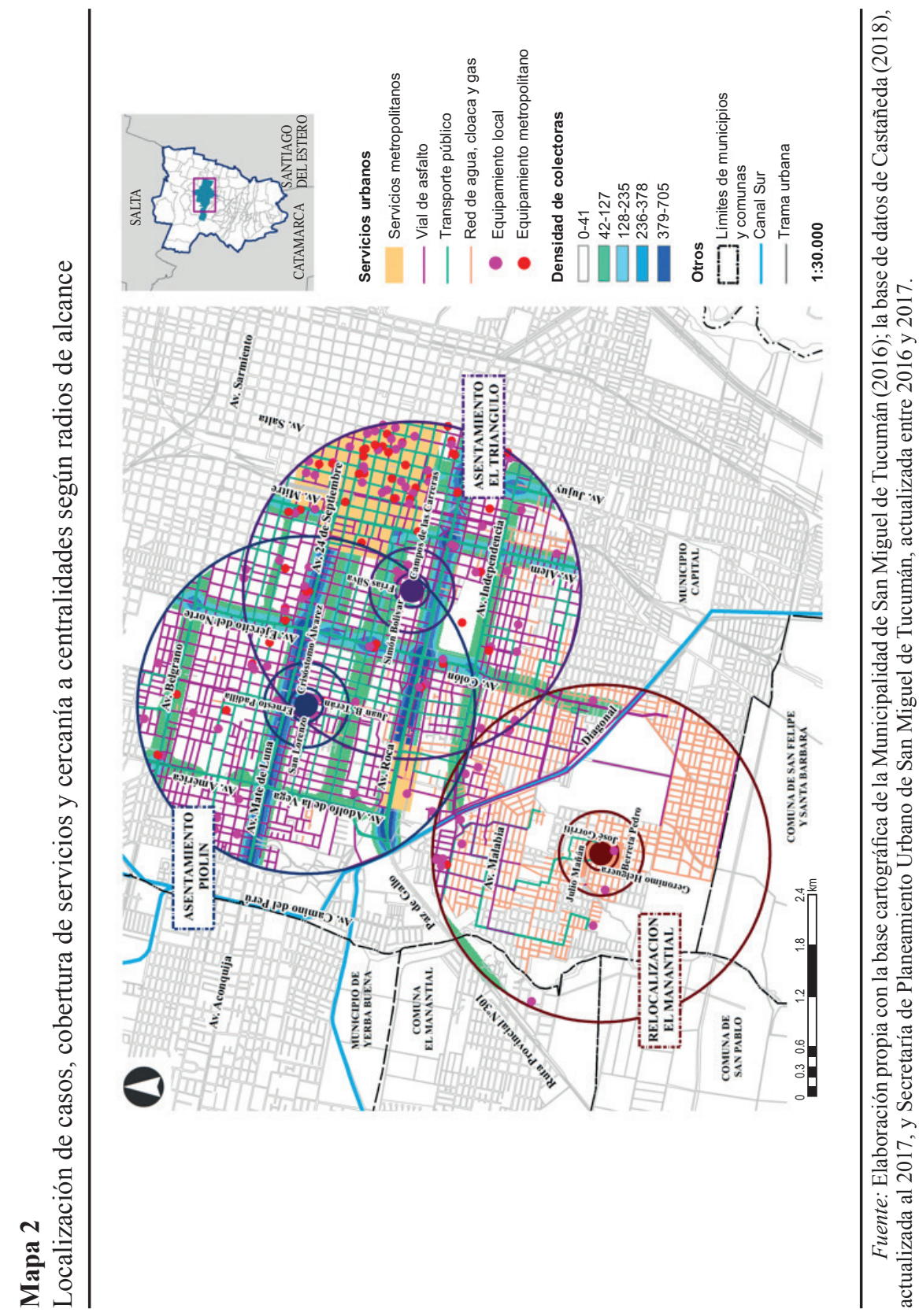




\section{Niveles de accesibilidad de las áreas de influencia}

Si bien se tiene en cuenta que los procesos de dotación de servicios se llevan a cabo de modo gradual una vez realizada la edificación residencial, en los casos de estudio se verifica que las políticas de mejora del hábitat basadas en la relocalización de urbanizaciones populares no mejoran la calidad de vida de la población relocalizada. A pesar de que a las familias se les entrega un módulo habitacional e incluso una vivienda mínima terminada, las condiciones de localización imponen una calidad de vida menor a la de la situación de origen.

Esto se demuestra en los costos extras en transporte que deben solventar los colonos para tener una accesibilidad similar a la anterior, situación que repercute fuertemente en sus economías familiares. Por lo tanto, lejos de beneficiar a los grupos relocalizados, se les castiga mandándolos a lugares con condiciones urbanas y habitacionales muy por debajo de las que tenían; tal como lo revelan los análisis realizados.

En materia de equipamientos educativos y sanitarios (locales y metropolitanos), cercanía a centralidades, cobertura de redes de agua, saneamiento, gas, vías de asfalto y cantidad de líneas de transporte público y colectoras, El Triángulo posee los mayores niveles de acceso y, por lo tanto, la situación más favorable de los tres barrios. El Piolín tiene una accesibilidad similar a la de El Triángulo, aunque con niveles mayores en algunos casos en el rango de los 0-200 m y menor distancia a las colectoras de transporte público. El Manantial posee la situación más desfavorable en todos los casos, con los niveles más bajos de acceso.

En el radio de alcance de los 0-200 m las condiciones de acceso en los tres casos son similares.

En el radio de los 200-500 m comienza a notarse la diferencia entre los asentamientos y el área de relocalización, ya que en todas las variables tenidas en cuenta, Manantial constituye el caso más desfavorable; a éste le sigue Villa Piolín, que posee menor cobertura de servicios. En el radio de los 5002000 metros, Manantial nuevamente constituye el caso más desfavorable en todas las variables; le sigue Villa Piolín, que posee menor cobertura de servicios que El Triángulo.

De esta manera, tanto Villa Piolín como El Triángulo se encuentran localizados en áreas donde la accesibilidad es muy alta, alta e intermedia; mientras que en Manantial Sur ésta disminuye a baja y muy baja (Mapa 3). 


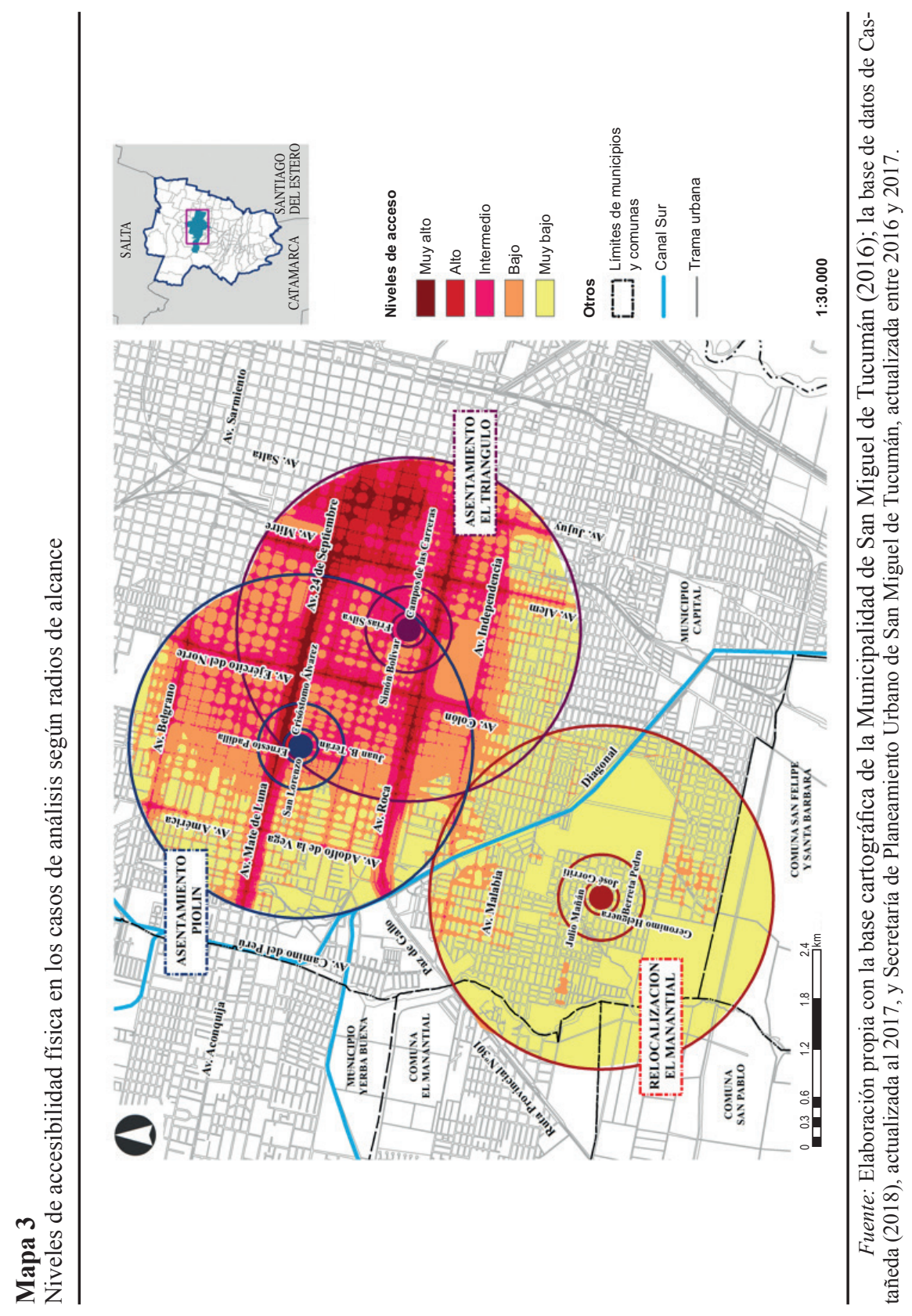




\section{Conclusiones}

Conceptualizando respecto al efecto de la relocalización de los hogares en el lugar donde han sido desplazados, podría concluirse que hay pérdida de calidad de vida de los mismos debida a distintas cuestiones.

Por un lado, por la disminución de la oferta de infraestructuras (agua, gas, cloaca, vialidades y transporte público) y de equipamientos (salud, educación y centralidades). En general, esta reducción en la oferta tiene un efecto directo en la economía de los hogares, que deben afrontar un gasto superior en tiempo y dinero para acceder a servicios similares a los de la localización de origen. El acceso a dotaciones de salud y educación es francamente menor, especialmente en los equipamientos de carácter metropolitano, lo que significa una pérdida para los hogares en el acceso a los servicios más especializados.

La disminución en la oferta de transporte público y en la calidad del tipo de vía impacta negativamente en las oportunidades de desarrollo familiar. Esto se ve agravado por la presencia de numerosas barreras físicas propias de una zona periférica en reciente desarrollo y urbanización, con presencia de grandes vacíos con malezas y basurales, canales de desagüe sin cruces peatonales ni vehiculares, y calles precarias, entre otros problemas. De este modo, la etapa inicial de desarrollo por parte del Estado de una urbanización popular como Manantial I y II supone la creación de "islas" populares en una periferia inconclusa, incomunicada y desarticulada del resto de la red urbana.

Otro aspecto que incide directamente en la pérdida de calidad de vida de la población son las malas condiciones ambientales en el sector de destino.

La presencia de pozos sépticos sin tapas, debido al robo denunciado por vecinos en reiteradas notas en la prensa local, favorece la difusión de malos olores. Éstos también proliferan debido a la presencia de basurales en terrenos baldíos adyacentes y en las calles, las cuales no poseen asfalto ni cordón cuneta, lo que, además, aumenta los riesgos de inundación de la zona por ausencia de un sistema de desagüe que permita el escurrimiento de las aguas superficiales.

También contribuye a la pérdida de calidad de vida la falta de seguridad que denuncian los vecinos, debido a que las colectoras de transporte se encuentran lejos y poco accesibles por el mal estado de las calles, a la ausencia de iluminación pública en tramos y a la presencia de baldíos, entre otros.

Respecto a los cambios en el nivel socioeconómico de la población predominante en la localización de origen, se puede observar (Foto 2) cómo ambos casos constituyen claros ejemplos de "un proceso de transformación 
social en forma de gentrificación, es decir, ocupación por clases altas o medias de lo que habían sido barrios populares", en palabras de Delgado (2007), con la consiguiente expulsión de los pobres de localizaciones urbanas relativamente centrales hacia la periferia de la ciudad.

Estas operaciones de expulsión se realizan mediante la articulación de acciones entre la administración pública, el IPV, que construye el barrio para el traslado, la municipalidad propietaria del suelo original y que ejecuta las obras posteriores de parquización, y los emprendedores inmobiliarios que desarrollan o han desarrollado importantes inversiones en las proximidades (Tucumán Center, en el caso de Villa Piolín). También es importante resaltar que el proceso de erradicación y traslado fue muy conflictivo debido a la fuerte oposición que presentaron los vecinos (Foto 1). Este tema fue motivo de numerosas noticias en la prensa local, que denunciaba la fuerte presión de los colonos contra el abandono de sus hogares de origen.

A cuatro años de la erradicación de ambos asentamientos, resulta evidente el desarrollo del sector de origen no sólo por la presencia de nuevos espacios verdes en los terrenos del exasentamiento, sino también por la renovación urbana del sector, con gran cantidad de anuncios de promociones futuras y con la mayor oferta de ventas y alquileres de inmuebles.

Los barrios populares relocalizados perduran en una condición insular, aislados de la trama urbana, marginados de la ciudad formal, siendo sometidos periódicamente -según el cambio de gobierno- a políticas, programas o proyectos para mejorar la calidad de vida y fomentar su integración a la urbe. Adquieren, con el paso del tiempo, una fuerte estigmatización social de barrio o zona pobre dentro del AMeT, sumada a la pérdida de identidad que sufren las familias relocalizadas producto del desarraigo, puesto que la identidad urbana constituye un servicio público básico para generar la integración urbana. De hecho, éste es uno de los aspectos que más se trabaja en la región latinoamericana en las últimas actuaciones, catalogadas como "buenas prácticas urbanas".

Este proceso, que viene observándose desde hace más de treinta años (Gómez López, 2001), perdurará en tanto no se resuelvan los problemas estructurales que sólo pueden ser afrontados o delineados desde un planeamiento integral del AMeT.

Por otro lado, los programas como el Fedevilla, manejados con criterios de concentración como lo hizo el IPVDU local, terminan aglutinando los asentamientos relocalizados en un megaemprendimiento del AMeT, en este caso Manantial I y II. Esta política de aglomeración de barrios populares no es adecuada desde el punto de vista de su integración socioespacial. Se crean vastas zonas de barriadas pobres, con gran potencialidad de convertirse en 
guetos, zonas rojas, impenetrables por la policía y socialmente muy estigmatizadas, contrarias a los intentos y buenas prácticas urbanas actuales respecto a articular, vincular y permeabilizar los sectores populares con el resto de la ciudad.

\section{Bibliografía}

Ardila, R. (2003). Calidad de vida: una definición integradora. Revista Latinoamericana de Psicología, 35(2), 161-164. Recuperado de http:// www.redalyc.org/articulo.oa?id=80535203

Barajas Bustillos, H. A y Gutiérrez Flores, L. (2012). La importancia de la infraestructura física en el crecimiento económico de los municipios de la frontera norte. Estudios Fronterizos, 13(25), 57-88. Recuperado de http://www.scielo.org.mx/scielo.php?script=sci_arttext\&pid=S0187$69612012000100003 \& \operatorname{lng}=\mathrm{es} \& \operatorname{lng}=\mathrm{es}$

Beuf, A. (2011). Nuevas centralidades y acceso a la ciudad en las periferias bogotanas. Bulletin de l'Institut Français d'Études Andines, 40(1), 147178. Recuperado de http://journals.openedition.org/bifea/1663

Blanco, J., Bosoer, L. y Apaolaza, R. (2014). Gentrificación, movilidad y transporte: aproximaciones conceptuales y ejes de indagación. Revista de Geografia Norte Grande, 58, 41-53. Recuperado de http://www. redalyc.org/articulo.oa? $\mathrm{id}=30031739003$

Boldrini, P. (2011). Producción participativa del hábitat popular en el Área Metropolitana de San Miguel de Tucumán (Tesis doctoral en Ciencias Sociales). Universidad Nacional de Tucumán, Argentina.

Boldrini, P., Del Castillo, A. y Malizia, M. (2014). Condiciones de vida y fragmentación socio-espacial en el aglomerado Gran San Miguel de Tucumán (noroeste argentino). Estudios Socioterritoriales, 15, 15-43. Recuperado de http://ri.conicet.gov.ar/handle/11336/31569

Boldrini, P. y Malizia, M. (2014). Procesos de gentrificación y contragentrificación. Los mercados de Abasto y del Norte en el Gran San Miguel de Tucumán (noroeste argentino). Revista INVI, 29(81), 157-191. Recuperado de http://revistainvi.uchile.cl/index.php/INVI/article/view/811/1157

Breilh, J. (2010). La epistemología crítica: una nueva forma de mirar la salud en el espacio urbano. Salud Colectiva, 6(1), 83-101. Recuperado de http://www.redalyc.org/articulo.oa?id=73115246007

Breilh, J. (2013). La determinación social de la salud como herramienta de transformación hacia una nueva salud pública (salud colectiva). Revista Facultad Nacional Salud Pública, 31(1), 13-27. Recuperado de http:// 
aprendeenlinea.udea.edu.co/revistas/index.php/fnsp/article/view/ $16637 / 20779752$

Buzai, G. y Baxendale, C. (2008). Modelos de localización-asignación aplicados a servicios públicos urbanos: análisis espacial de escuelas de EGB en la ciudad de Luján. Revista Universitaria de Geografía, 17, 233-254. Recuperado de http://www.scielo.org.ar/pdf/reuge/v17n1/ v17n1a10.pdf

Castañeda, A. L. (2018). Metodología de detección de umbrales ambientales en base a los servicios urbanos. Un aporte a la evaluación del área metropolitana de Tucumán (Tesis doctoral en Ciencias Sociales). Universidad Nacional de Tucumán, Argentina.

Castañeda, A., Malizia, M. y Boldrini, P. (2018). Las centralidades como expresión de la desigualdad urbana. En M. Malizia, P. Boldrini, P. Paolasso (coords.), Hacia otra ciudad posible. Transformaciones urbanas recientes en el aglomerado Gran San Miguel de Tucumán (pp. 97-123). Buenos Aires: Café de las Ciudades.

Comunicados de prensa IPVDU. (2013). El IPV comenzó la construcción de Manantial Sur, IPVDU, Tucumán, Argentina, 16 de agosto.

Contexto. (2016). Corrupción: 400 casas adjudicadas, vacías y en venta en Manantial Sur. Contexto, Tucumán, Argentina, 28 de marzo.

Contreras, E. y Pacheco, J. F. (2007). Evaluación multicriterio para programas y proyectos públicos (Documentos de Trabajo, 92). Santiago de Chile: Universidad de Chile.

Cuozzo, R. (2018). Transformaciones territoriales: nuevas dinámicas en la producción del suelo residencial en el Área Metropolitana de Tucumán (Tesis doctoral en Ciencias Sociales). Universidad Nacional de Tucumán. Argentina,

Dangond Gibsone, C., Jolly, J., Monteoliva Vilches, A. y Rojas Parra, F. (2011). Algunas reflexiones sobre la movilidad urbana en Colombia desde la perspectiva del desarrollo humano. Papel Político Bogotá, 16(2), 485-514. Recuperado de http://www.scielo.org.co/pdf/papel/ v16n2/v16n2a07.pdf

Delgado, M. (2007). La ciudad mentirosa. Fraude y miseria del modelo Barcelona, Madrid: Catarata.

Figueroa, O. (2005). Transporte urbano y globalización. Políticas y efectos en América Latina. Eure, Revista Latinoamericana de Estudios Urbanos Regionales, 31(94), 41-53. Recuperado de http://www.scielo.cl/pdf/eure/ v31n94/art03.pdf

Figueroa, O. (2013). Gestión de la infraestructura y de los servicios urbanos: ¿demanda solvente o solvencia territorial? Eure, Revista Latinoameri- 
cana de Estudios Urbanos Regionales, 39(117), 237-241. Recuperado de http://www.eure.cl/index.php/eure/article/view/1438

Gómez López, C. (2001). Influencia de la promoción pública de vivienda en el desarrollo de la mancha urbana de la ciudad de San Miguel de Tucumán. Elementos para la comprensión de su estructura urbana (Tesis doctoral). Universidad Politécnica de Valencia, España.

Gómez López, C., Cuozzo, R. L. y Boldrini, P. (2015). Impactos de las políticas públicas de hábitat en la configuración del espacio urbano entre 2003 y 2013. El caso del Área Metropolitana de Tucumán, Argentina. Cuaderno Urbano, 19(19), 153-178. Recuperado de http://www.scielo. org.ar/scielo.php?script=sci_arttext\&pid=S1853-36552015000400008

Guevara, H., Domínguez, A., Ortunio, M., Padrón, D. y Cardozo, R. (2010). Percepción de la calidad de vida desde los principios de la complejidad. Revista Cubana de Salud Pública, 36(4), 357-360. Recuperado de https:// scielosp.org/scielo.php?pid=S0864-34662010000400011\&script=sci arttext\&tlng=en

Gutiérrez, A. (2000). La producción del transporte público en la metrópoli de Buenos Aires: cambios recientes y tendencias futuras. Eure, Revista Latinoamericana de Estudios Urbanos Regionales, 26(77), 109-136. Recuperado de http://dx.doi.org/10.4067/S0250-71612000007700005

Hernández Aja, A. (2009). Calidad de vida y medio ambiente urbano: indicadores locales de sostenibilidad y calidad de vida. Revista INVI, 24(65), 79-111. Recuperado de http://dx.doi.org/10.4067/S0718-83582009 000100003

Instituto Nacional de Estadística y Censos. (2010). Censo Nacional de Población, Hogares y Vivienda (INDEC). Argentina. Recuperado de https:// www.indec.gob.ar/indec/web/Nivel4-Tema-2-41-135

Kogan, J. y Bondorevsky, D. (2016). La infraestructura en el desarrollo de América Latina. Economía y Desarrollo, 156(1), 168-186. Recuperado de http://scielo.sld.cu/scielo.php?script=sci_arttext\&pid=S0252$85842016000100012 \& \operatorname{lng}=\mathrm{es} \& \operatorname{tlng}=\mathrm{es}$

La Gaceta. (2003). Villa El Triángulo. La Gaceta, Tucumán, Argentina, 11 de marzo.

La Gaceta. (2010). Villa Piolín, o el nudo de la inseguridad. La Gaceta, Tucumán, Argentina, 20 de julio.

La Gaceta. (2013). Desde marzo, 58 familias esperan irse de la villa. $L a$ Gaceta, Tucumán, Argentina, 1 de octubre.

La Gaceta. (2014). Las familias de El Triangulito se despiden y se trasladan a el Manantial. La Gaceta, Tucumán, Argentina, 16 de mayo. 
La Gaceta. (2014a). Se llevaron las casas de El Triangulito y comenzó a crecer el basural. La Gaceta, Tucumán, Argentina, 4 de junio.

La Gaceta. (2014b). Hoy se realizará el traslado de Villa Piolín. La Gaceta, Tucumán, Argentina, 3 de noviembre.

La Gaceta. (2014c). Desde adentro: cómo era vivir en Villa Piolín. La Gaceta, Tucumán, Argentina, 5 de noviembre.

La Gaceta. (2014d). La provincia planea comprar el predio de Villa Piolín. La Gaceta, Tucumán, Argentina, 5 de noviembre.

La Gaceta. (2014e). La Provincia pagará \$2 millones por el predio de Villa Piolín. La Gaceta, Tucumán, Argentina, 6 de noviembre.

Lange Valdés, C. (2011). Dimensiones culturales de la movilidad urbana. Revista INVI, 26(71), 87-106. Recuperado de http://revistainvi.uchile. cl/index.php/INVI/article/view/531/562

Longhi, F., Bolsi, A., Velázquez, G., Paolasso, P. y Celemín, J. P. (2015). Fragmentación socio-territorial y condiciones de vida en Argentina en los albores del siglo XXI. Revista Latinoamericana de Población, 7(12), 99-131. Recuperado de http://www.redalyc.org/articulo.oa?id=32 3830084004

Magrinyà Torner, F. (2005). El acceso a los servicios urbanos y la urbanización en los países del Sur: la necesidad de una perspectiva en el espacio y en el tiempo. Cuadernos Internacionales de Tecnología para el Desarrollo Humano, 3, 1-10. Recuperado de https://upcommons.upc.edu/ bitstream/handle/2099/1597/15_El_acceso.pdf

Manrique Gómez, A. S. (2013). Gentrificación de La Candelaria: reconfiguraciones de lugar de residencia y consumo de grupos de altos ingresos. Revista Colombiana de Geografía, 22(2), 211-234. Recuperado de https://revistas.unal.edu.co/index.php/rcg/article/view/24940/pdf_280

Mayorga, M. y Fontana, M. P. (2012). Espacios de centralidad urbana y redes de infraestructura. La urbanidad en cuatro proyectos urbanos. Bitácora Urbano Territorial, 21(2), 123-138. Recuperado de https://revistas.unal. edu.co/index.php/bitacora/article/view/29084

Ministerio del Interior, Obras Públicas y Vivienda. (2014). Estudio de diagnóstico del Área Metropolitana de Tucumán (EDAMET). Programa de Desarrollo de Áreas Metropolitanas del Interior (DAMI). Tucumán, Argentina: Ministerio del Interior, Obras Públicas y Vivienda, Unidad Ejecutora Central / Universidad Nacional de Tucumán. Recuperado de http://dami.uec.gov.ar/wp-content/uploads/2014/08/dami.uec.gov.ar_in forme-de-situacion-del-area-metropolitana-de-tucuman-2014.-informefinal.pdf 
Municipalidad de San Miguel de Tucumán. (2016). Entregaron 190 viviendas en el barrio Manantial Sur, que ya cuenta con servicio de recolección de residuos. Municipalidad de San Miguel de Tucumán, Argentina, 29 de noviembre.

Navarrete Rodríguez, P. E. y Andrade Vallejo, M. A. (2010). La infraestructura del transporte público urbano en la Ciudad de México y su relación con las políticas públicas. Investigación Administrativa, 39(105), 41-59. Recuperado de http://www.redalyc.org/articulo.oa?id=456045211003

Obregón Biosca, S. A. y Betanzo Quezada, E. (2015). Análisis de la movilidad urbana de una ciudad media mexicana. Caso de estudio: Santiago de Querétaro. Economía, Sociedad y Territorio, 15(47), 61-98. Recuperado de http://www.redalyc.org/pdf/111/11132816004.pdf

Olivera, T. (2013). Comenzó la construcción de Manantial Sur. Revista Consejo Nacional de la Vivienda, 41, 63-66.

Porro, N. y Mesa, A. (2016). Estudio del fenómeno de centralidad urbana mediante una metodología sistémica aplicada a la dinámica espacial de un área metropolitana. El caso de Mendoza, Argentina. Urbano, 19(33), 44-53. Recuperado de http://revistas.ubiobio.cl/index.php/RU/article/ view/2367

Prado Ríos, L. (2001). La centralidad urbana. En F. Carrión (ed.), La ciudad construida, urbanismo en América Latina (pp. 289-295). Quito, Ecuador: Flacso-Ecuador.

Rodríguez Vignoli, J. (2008). Movilidad cotidiana, desigualdad social y segregación residencial en cuatro metrópolis de América Latina. Eure, Revista Latinoamericana de Estudios Urbanos Regionales, 34(3), 49-71. Recuperado de http://dx.doi.org/10.4067/S0250-71612008000300003

Satriano, C. (2006). Pobreza, políticas públicas y políticas sociales. MAD, Revista del Magíster en Antropología Aplicada y Desarrollo, 15, 60-73. Recuperado de https://revistamad.uchile.cl/index.php/RMAD/article/ view/14021/14325

Schwartzmann, L. (2003). Calidad de vida relacionada con la salud: aspectos conceptuales. Ciencia y Enfermería, 9(2), 9-21. Recuperado de http:// dx.doi.org/10.4067/S0717-95532003000200002

Secretaría de Estado de Comunicación Pública del Gobierno de Tucumán. (2016). Manantial Sur: 190 familias ya tienen casa propia. Secretaría de Estado de Comunicación Pública del Gobierno de Tucumán, Tucumán, Argentina, 26 de noviembre.

Smith, N. (2012). La nueva frontera urbana. Ciudad revanchista y gentrificación, Madrid, España: Traficantes de Sueños.

Tonón, G. y Castro Solano, A. (2012). Calidad de vida en Argentina: percep- 
ciones macro y micro sociales. Estudios Políticos, 27, 157-171. Recuperado de http://www.scielo.org.mx/scielo.php?script=sci_arttext \&pid=S0185-16162012000300009\&lng=es\&nrm=iso

Tucumán Primicias (2015). A un año del traslado de Villa Piolín, la plaza es aún una promesa. Tucumán Primicias, Argentina, 26 de noviembre.

Urzúa, A. y Caqueo-Urizar, A. (2012). Calidad de vida: una revisión teórica del concepto. Terapia Psicológica, 30(1), 61-71. Recuperado de http:// dx.doi.org/10.4067/S0718-48082012000100006

Valenzuela, L. (2005). Periferia e infraestructura en el Paradero 14. Revista $A R Q, 60,62-64$. Recuperado de https://dx.doi.org/10.4067/S0717-699 62005006000011

Velázquez, G. (2001). Geografía y bienestar: situación local, regional y global de la Argentina luego del censo 2001. Buenos Aires, Argentina: Eudeba.

Velázquez, G. y Celemín, J. P. (2013). La calidad ambiental en la Argentina: análisis regional y departamental 2010. Argentina: Universidad del Centro de la provincia de Buenos Aires.

Wainstein Krasuk, O. y Brandariz, G. (2014). Ciudades inclusivas. Estrategias de intervencion. Hacia ciudades inclusivas. Buenas prácticas. Buenos Aires, Argentina: Concentra.

\section{Acerca de las autoras}

Ana Laura Castañeda Nordmann es doctora en Ciencias Sociales por la Universidad Nacional de Tucumán Argentina (UNT), maestra en Desarrollo Económico Regional y Local y Gestión del Territorio por la Universidad de Valladolid, España (UVA) y arquitecta por la UNT. Actualmente es becaria postdoctoral del Consejo Nacional de Investigaciones Científicas y Técnicas (Conicet), con sede de trabajo en el Centro de Estudios sobre el Territorio y el Hábitat Popular (CETyHaP), docente auxiliar de Teoría de la Arquitectura y La Vivienda Social, y consejera de Posgrado del Instituto de Arquitectura de la Facultad de Arquitectura (FAU) de la UNT. Sus temas de investigación son: habitabilidad urbana, prácticas y políticas públicas de servicios. ORCID: https://orcid.org/0000-0002-9171-1961

Entre sus publicaciones destacan:

Gómez López, C. y Castañeda, A. (2019). Revisión crítica sobre la construcción de vivienda estatal y el acceso a servicios urbanos en el área metropolitana de Tucumán. Oculum Ensaios Ensaios. Revista de Arquitetura e Urbanismo, 16(2), 257-275. 
Castañeda, A., Malizia, M. y Boldrini, P. (2018). Las centralidades como expresión de la desigualdad urbana. En M. Malizia, P. Boldrini y P. Paolasso (comps.), Hacia otra ciudad posible. Transformaciones urbanas recientes en el aglomerado Gran San Miguel de Tucumán. Buenos Aires: Café de las Ciudades.

Claudia Fernanda Gómez López es doctora en Urbanismo por la Universidad Politécnica de Valencia, España (UPV), especialista internacional en Ordenación Territorial y Medio Ambiente por la UPV y arquitecta por la Universidad Nacional de Tucumán, Argentina (UNT). Actualmente es profesora titular de Teoría de la Arquitectura, La Vivienda Social y Habitar la Arquitectura, y directora del Centro de Estudio sobre el Territorio y el Hábitat Popular (CETYHaP) de la Facultad de Arquitectura (FAU) de la UNT; es investigadora categoría 1 del Sistema Nacional de Incentivos; directora de Programas de Investigación de la UNT; y docente en cursos de posgrado como el doctorado en Arquitectura y la especialización en Arquitectura Sustentable de la FAU-UNT, el doctorado en Agrimensura de la Universidad Nacional de Catamarca, Argentina (UNCA), la maestría en Gestión Ambiental de la UNT y la maestría en Ingeniería Ambiental de la Universidad Tecnológica Nacional de Tucumán, Argentina (UTN). Sus temas de investigación son el crecimiento urbano y las políticas públicas de vivienda. ORCID: https://orcid.org/0000-0002-0575-9388

Entre sus publicaciones destacan:

Gómez, López, C. y Castañeda, A. (2019). Revisión crítica sobre la construcción de vivienda estatal y el acceso a servicios urbanos en el área metropolitana de Tucumán. Oculum Ensaios. Revista de Arquitetura e Urbanismo, 16(2), 257-275.

Gómez, López, C. y Cuozzo, R. (2018). Las tendencias del crecimiento metropolitano. En M. Malizia, P. Boldrini y P. Paolasso (comps.), Hacia otra ciudad posible. Transformaciones urbanas recientes en el aglomerado Gran San Miguel de Tucumán. Buenos Aires: Café de las Ciudades.

Recepción: 23 de enero de 2018.

Aceptación: 18 de agosto de 2018. 